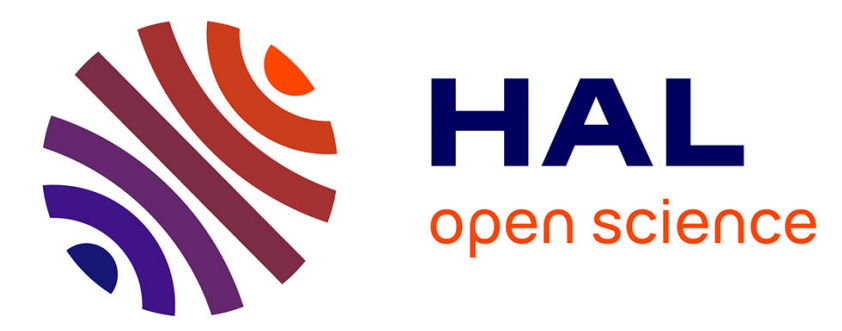

\title{
Experimental investigations of void dynamics in a dusty discharge
}

\author{
Maxime Mikikian, Laifa Boufendi
}

\section{To cite this version:}

Maxime Mikikian, Laifa Boufendi. Experimental investigations of void dynamics in a dusty discharge. Physics of Plasmas, 2004, 11 (8), pp.3733. 10.1063/1.1761578 . hal-00431203

\section{HAL Id: hal-00431203 https://hal.science/hal-00431203}

Submitted on 10 Nov 2009

HAL is a multi-disciplinary open access archive for the deposit and dissemination of scientific research documents, whether they are published or not. The documents may come from teaching and research institutions in France or abroad, or from public or private research centers.
L'archive ouverte pluridisciplinaire HAL, est destinée au dépôt et à la diffusion de documents scientifiques de niveau recherche, publiés ou non, émanant des établissements d'enseignement et de recherche français ou étrangers, des laboratoires publics ou privés. 


\title{
Experimental investigations of void dynamics in a dusty discharge
}

\author{
Maxime Mikikian and Laïfa Boufendi* \\ Groupe de Recherches sur l'Energétique des Milieux Ionisés \\ Université d'Orléans, 45067 Orléans Cedex 2, France
}

\begin{abstract}
We report on first electrical and spectroscopic characterizations of an instability, usually called "heartbeat" instability, occurring in a laboratory dusty plasma. It consists of successive contractions and expansions of the central dust free region observed in a dense cloud of dust particles. This cloud is formed in a radio-frequency plasma by sputtering polymer material deposited on the electrodes. The evolution of the discharge current reveals the relatively complex shape of the instability and allows to measure its evolution as a function of gas pressure and radio-frequency power.
\end{abstract}

PACS numbers: 52.25.Vy, 52.27.Lw, 52.35.Ra

\section{INTRODUCTION}

The formation of dust particles in low pressure plasmas is actively studied [1] since their discovery in plasma processing reactors $[2,3]$. In laboratory experiments, this formation is usually achieved by two different ways: using reactive gases such as silane [4-6] or using a target sputtered by the ion bombardment coming from the plasma [7-10]. In capacitively coupled radio-frequency discharges, these two methods usually lead to the formation of a dense cloud of submicron dust particles filling the whole gap between the electrodes. The dust particles are trapped in the discharge due to the negative charge they acquire in the plasma [11-13]. Their position is fixed by the balance of the various forces acting on them and principally due to the ions, the electrical fields, the thermal gradients, the gas flow and gravity. This last force plays an important role and consequently three-dimensional (3D) clouds can be obtained in laboratory only with submicron dust particles. With bigger particles $(\gtrsim 1 \mu \mathrm{m})$, 3D clouds can be formed under microgravity conditions $[14,15]$ or using an additional force like thermophoresis to counterbalance gravity [16]. When this cloud is obtained, experiments show that the central region of the plasma is free of dust particles [17-20]. The formation of this egg-shaped region, usually called "void", is still actively studied [21-26] and it seems that the dust particles are pushed away from this region by the ion drag forces acting on these negatively charged dust particles. This structure is usually stable but sometimes a self-excited instability occurs, characterized by a low frequency oscillation of the void size known as the "heartbeat" instability. It has been previously observed during microgravity experiments [27] with a frequency around $1.5 \mathrm{~Hz}$ in a cloud of micron-sized dust particles and theoretical works [19] proposed that this oscillation is related to a modulation of the ionization rate. In this paper we report on the formation of this instability in lab-

*Electronic address: laifa.boufendi@univ-orleans.fr oratory and on the correlation between the void dynamics and the discharge characteristics such as current transport and optical emission. After describing our major observations concerning the void formation, new experimental results are presented, emphasizing the complex shape of this instability.

\section{EXPERIMENTAL SETUP}

The work presented here is performed in the PKENefedov (Plasma Kristall Experiment) chamber designed for microgravity experiments $[14,15]$. The experimental setup consists in a parallel plate $(4 \mathrm{~cm}$ in diameter separated by $3 \mathrm{~cm}$ ) rf discharge operating in push-pull excitation mode $(0-4 \mathrm{~W})$. Dust particles are grown in an argon plasma $(0.2-2$ mbar $)$ from a sputtered polymer layer deposited on the electrodes and coming from previously injected dust particles (3.4 $\mu \mathrm{m}$, melamine formaldehyde). The cloud is illuminated by a thin laser sheet perpendicular to the electrodes and the scattered light is recorded at $90^{\circ}$ with standard charge-coupled device (CCD) cameras with 25 images per second. A detailed description of this experiment and previous results are presented in References [28-30].

\section{DUST PARTICLE GROWTH AND VOID FORMATION}

Depending on the experimental conditions, the growth process leads to various shapes of the dust cloud (few layers, domelike shape, 3D dense cloud) and is highly sensitive to the gas purity as previously reported [20]. This effect, well observed on successive runs [31], is amplified by the fact that the experiments are performed without gas flow (static pressure). We need to pump down during a sufficiently long time (at least one hour) between each experiment in order to eliminate the species formed during the previous run and coming from the outgassing of the walls and from the sputtered matter. Indeed, a very high dust density has been achieved recently by op- 


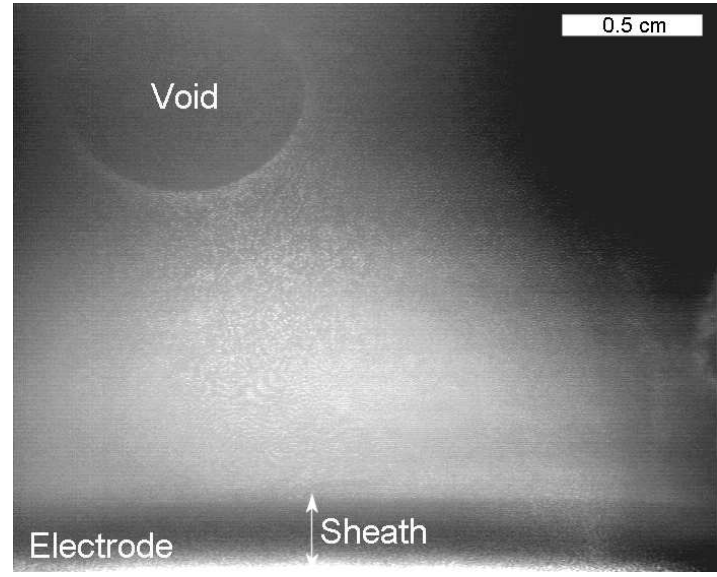

FIG. 1: (Color online). Cloud of submicron particles with a clear void structure in the center of the plasma.

timizing the pumping system leading to a better base pressure (few $10^{-6}$ mbar actually instead of few $10^{-5}$ mbar before). The working pressure is $1.6 \mathrm{mbar}$ and the rf power is around $2.8 \mathrm{~W}$. When a high dust density is reached, the dust particle size is very small (few hundreds of nanometers using scanning electron microscopy) and a cloud without a clear void can be obtained. After this step, we usually see the progressive formation of the void (Figure 1) but sometimes the plasma switches off by itself due to very high concentration of dust particles attaching the free electrons. A mixture of chaotic behaviour and instabilities with well defined frequencies [31] (different from the broadband "filamentary mode" [18, 20]) appears sometimes in the discharge current during dust particle growth. However, it seems to be not indispensable for the void formation. At low power, the plasma is more sensitive to any internal modification and if the void is small (few $\mathrm{mm}$ ), its frontiers become less defined and some dust particles begin to cross this region [32]. Then, more and more dust particles cross the void and the plasma switches off by itself. Increasing the power prevents any particles to enter in this region. This observation underlines the role of the forces responsible for the void formation like the ion drag force. When the coupled power to the plasma decreases, the forces pushing away the dust particles from the center cannot maintain a stable size of the void.

\section{VOID INSTABILITY AND ELECTRICAL MEASUREMENTS}

Once the cloud is formed, increasing the rf power and decreasing the pressure enable the formation of the void and the generation of the heartbeat instability in a quite repetitive way. In the same manner, the size of the stable void is increased by increasing the power or by lowering the pressure [24]. From our observations it seems that this instability concerns only small voids appearing only
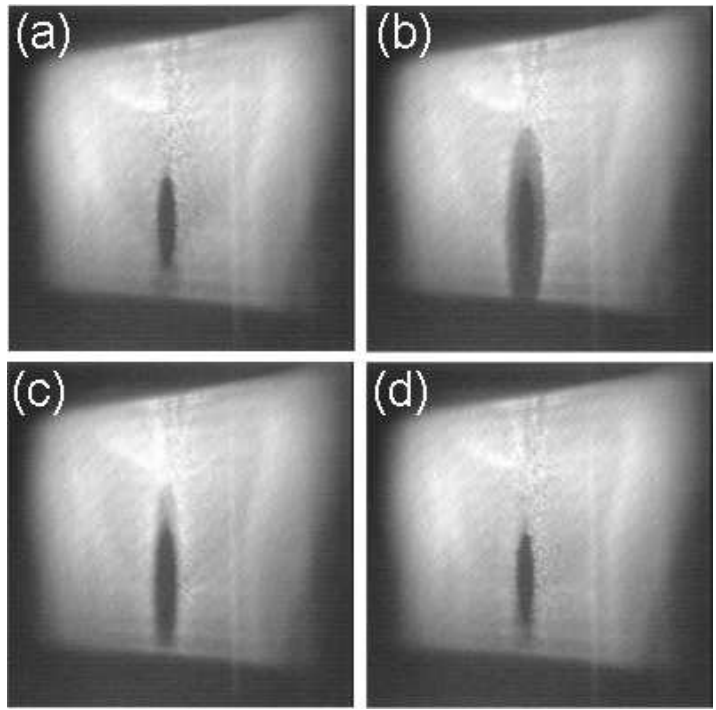

FIG. 2: (Color online). Consecutive frames taken at $\simeq 20^{\circ}-$ $30^{\circ}$ with respect to the laser direction during the heartbeat instability. The black region at the top is the upper sheath. The black region at the bottom marks the laser sheet limit.

when a huge density of small dust particles (few hundreds of nanometers) is produced. In these conditions, the scattering parameter $x=\frac{2 \pi r_{p}}{\lambda}>1$ where $\lambda$ is the laser wavelength $(685 \mathrm{~nm})$ and $r_{p}$ the particle radius. Thus, the scattered light is collected at an angle lying approximately between $20^{\circ}$ and $30^{\circ}$ with respect to the incident laser direction. Therefore, the images seem to be compressed in the horizontal direction and a perspective effect appears. Figure 2 shows four consecutive frames separated by $2 \mathrm{~ms}$ during a typical heartbeat instability with a frequency around $14 \mathrm{~Hz}$. We can distinguish the minimum size $(\simeq 6 \mathrm{~mm}$ in $(\mathrm{a})$ and $(\mathrm{d}))$ and maximum size $(\simeq 12 \mathrm{~mm}$ in $(\mathrm{b}))$ of the void. Moreover, the maximum size of the void during the instability seems bigger than the size of the stable void. Due to the standard video speed limitations it is not possible to study more in details the instability and high speed cameras must be used in the future. In consequence we have studied the instability by measuring the amplitude of the fundamental harmonic of the discharge current. These measurements have been performed in various conditions of power and pressure during the same run assuming that the dust cloud remains unchanged in terms of particle density and size. Other runs have proved that the results are qualitatively reproducible even if small variations in the instability frequency or shape are observed.

The evolution of the instability as a function of the pressure at constant injected power $(3.3 \mathrm{~W})$ and as a function of the power at constant pressure (0.6 mbar) is presented respectively in Figures 3 and 4 . The time and amplitude scales are kept constant in order to point out the evolution in frequency and amplitude. The measured frequencies are compiled in Figure 5. Concerning the pressure effect, the first remark is the evolution of 

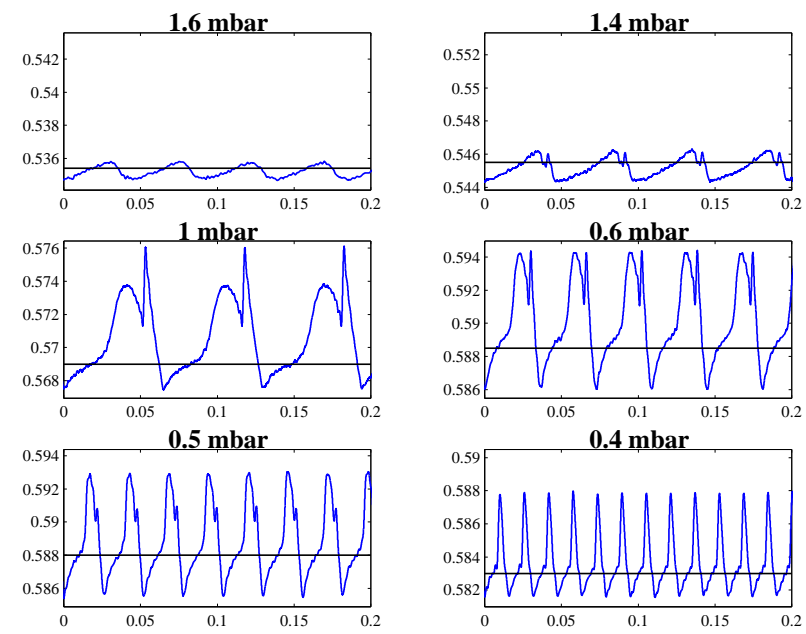

FIG. 3: (Color online). Pressure dependence of the electrode current during the heartbeat instability. The $\mathrm{x}$-axis is time in seconds and the y-axis is the current amplitude in arbitrary units.
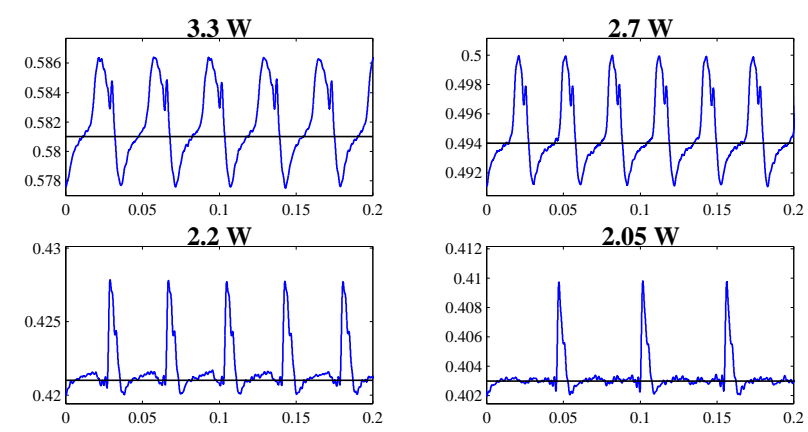

FIG. 4: (Color online). Power dependence of the electrode current during the heartbeat instability. The $\mathrm{x}$-axis is time in seconds and the y-axis is the current amplitude in arbitrary units.

the relative amplitude of the oscillation. Indeed, we start from a very small linear fluctuation at high pressure (1.6 mbar) which corresponds to a classical limit cycle in the phase space. Then, a bigger non linear oscillation appears at 1 mbar which slowly decreases when the pressure is lowered. At the same time, the frequency decreases slowly from $21 \mathrm{~Hz}$ at $1.6 \mathrm{mbar}$ to the minimum value of $15 \mathrm{~Hz}$ at 1 mbar. Then, as the pressure is still lowered, the frequency increases faster and faster to $27 \mathrm{~Hz}$ at 0.6 mbar and can attain more than $100 \mathrm{~Hz}$ at 0.3 mbar. Due to the low video sampling rate, the frequency cannot be correlated to the void size. The frequency increases slowly by decreasing the rf power and after a maximum value around $35 \mathrm{~Hz}$ it decreases certainly due to the fact that we are near the excitation threshold of this instability (Figure $4,2.05 \mathrm{~W}$ ). Indeed, below a given power the instability appears in an erratic way with sometimes a single contraction-expansion sequence in the middle of a stable sequence (open void corresponding to the continu-

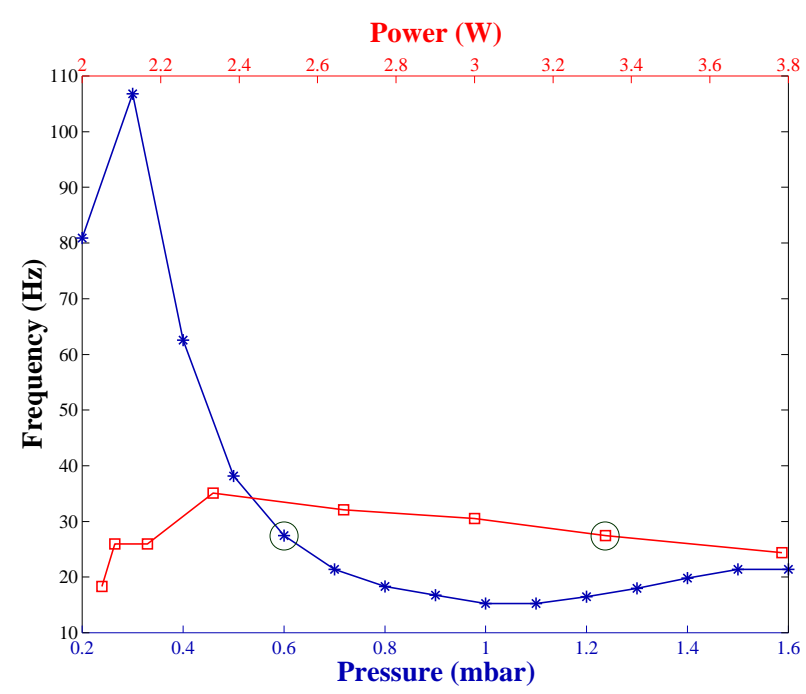

FIG. 5: (Color online). Evolution of the instability frequency as a function of pressure $(*)$ and power $(\square)$. Points in circles are taken in the same conditions (1.6 mbar, $3.3 \mathrm{~W})$.
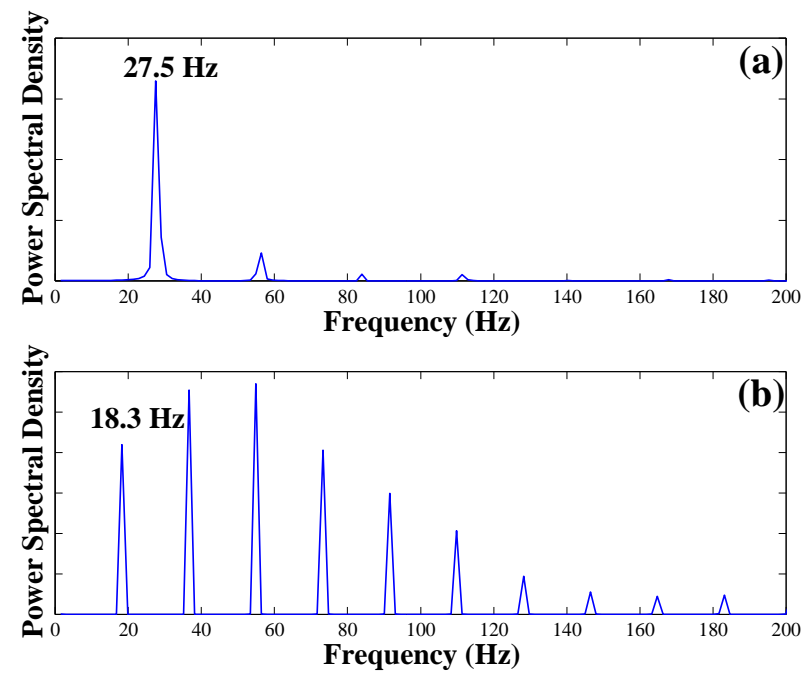

FIG. 6: (Color online). Fourier spectrum and oscillation frequency corresponding to Figure 4 , (a) at $3.3 \mathrm{~W}$, (b) at 2.05 W.

ous part of the signal). The fourier spectrum of the signal shows a clear peak at the oscillation frequency, for example at $3.3 \mathrm{~W}$ in Figure 6(a). When the power decreases, the oscillation shape becomes distorted and harmonics appear in the fourier space. Close to the threshold of the instability $(2.05 \mathrm{~W})$, the electrode current becomes a succession of Dirac functions and the fourier spectrum shows peaks centered at the harmonic frequencies (Figure $6(\mathrm{~b}))$. The fact that the dust cloud remained nearly unchanged during the measurements is confirmed by the similar signals recorded, with few minutes delay, at 0.6 mbar and 3.3 W (Figures 3, 4 and circles in Figure 5).

An other important observation coming from these curves is the complex shape of the instability. Indeed, 
we can distinguish various regions in the contractionexpansion sequence. When the instability occurs, the current amplitude oscillates around its stable value. If we take as a reference the curve obtained at $3.3 \mathrm{~W}$ in Figure 4, we observe first, a slow increase of the current which looks like a small shoulder. To correlate this part to a phase of the contraction-expansion sequence we must analyze an individual sequence or a succession of well separated ones as at 2.05 W. From these observations we can suppose that this stage follows the void contraction and is related to the void opening. Indeed, this part starts below the stable current value ( $\mathrm{dc}$ value, horizontal line at value 0 ), converges toward this value and then stay constant (static open void) until the next event. This stage is then followed by a faster increase which can be either the end of the expansion or the beginning of the contraction. The rest of the signal seems to correspond to the void contraction which appears relatively complex especially with the presence of a sharp peak. For example, in Figure 3 at 1 mbar the rising time of this peak is around $2 \mathrm{~ms}$ for a peak duration of approximately $6 \mathrm{~ms}$. We can see that this peak is not always clearly visible for example at $1.6 \mathrm{mbar}$ and decreases for low pressures. It has been observed during other runs and seems to behave always in the same way concerning its progressive decrease when the pressure is lowered. It appears always at the right hand side of the main oscillation and its correlation with a specific phase of the contraction-expansion sequence is still not clear. To perform a good analysis of these curves we must also think that when the current is changing very rapidly (as for example in the case of the sharp peak) the dust cloud cannot follow. Then, the evolution of the curves cannot be always correlated to the dust cloud motion and can indicate modifications of the plasma properties preceding the contraction or the expansion of the void.

\section{VOID INSTABILITY AND OPTICAL MEASUREMENTS}

The complex shape of the discharge current has been correlated to the evolution of the plasma light thanks to optical emission spectroscopy. The intensity of the $750.4 \mathrm{~nm}$ argon line has been recorded inside the void region during the instability and its evolution seems similar to the current (Figure 7(a) and (b)). Consequently, the expansion seems to be in good correspondance with an increase of the excitation rate and thus higher ionization leading to an increase of the ion outward force. At this time, the correlation between the two curves near the sharp peak is not clear due to a low signal to noise ratio for the emission signal and the very small time duration of the peak. The curves (c), (d) and (e) correspond to the line intensity outside the void and are recorded by moving the optic fiber horizontally towards the edge of the plasma. These curves show a deformation of the emission signal on the path of the void motion with a last

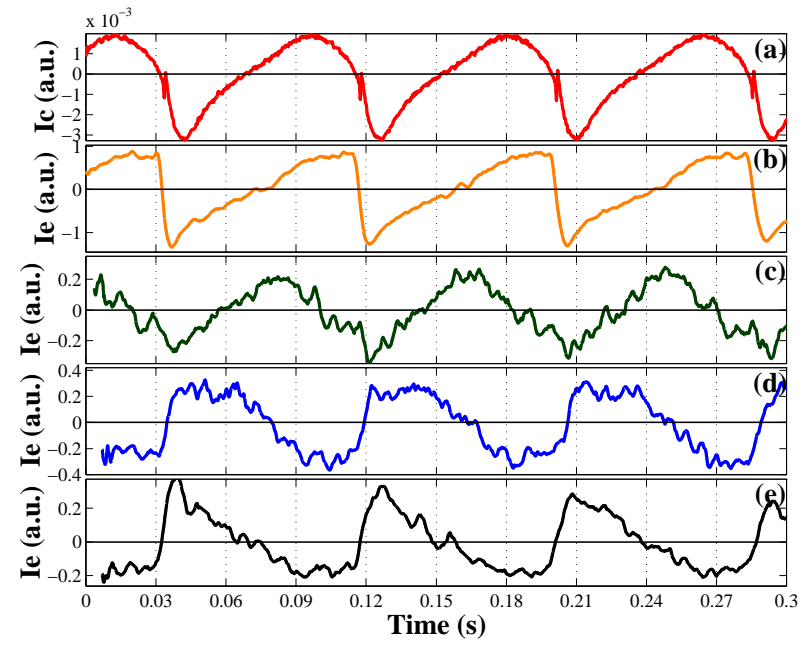

FIG. 7: (Color online). Electrode current $I_{c}$ (a), argon line $(750.4 \mathrm{~nm})$ intensity $I_{e}$ inside the void $(\mathrm{b})$, moving towards the plasma edge (c), (d), (e).

curve (e) symmetric of the signal taken in the center (b). This could underline the modification of the plasma local conditions driving (or due to) the dust cloud motion. Another remark concerning the optical results is a higher intensity of the emission line inside the void than outside. This effect is not appearing in the curves presented here because the continuous component has been suppressed but it can be "guessed" through the high signal to noise ratio in the void center. This effect is also very well seen with the naked eye where a bright ball of plasma is observed inside the void. This enhanced emission can be related to a higher density of argon metastables produced by the elevation of the electron temperature due to the electron attachment on the dust particles[31, 33, 34].

\section{CONCLUSION}

In this paper, we have presented new experimental results of a self-excited instability of the void called "heartbeat" instability. These results have been obtained under gravity condition with submicron dust particles. We have measured the instability frequency as a function of free parameters of the discharge and we have shown that the shape of this instability is not purely sinusoidal but relatively complex. The motion of the dust cloud and its correlation with the discharge current will be investigated in the future using high speed cameras. Optical emission spectroscopy allows to validate the current measurements and add a spatial information necessary to understand the behavior of the void region. 


\section{Acknowledgments}

The PKE-Nefedov chamber has been made available by the Max-Planck-Institute for Extraterrestrial Physics, Germany, under the funding of DLR/BMBF under grants No.50WM9852. The authors would like to thank M. Dudemaine for his electronic support. This work was supported by CNES under contract No.03/CNES/4800000132.
[1] A. Bouchoule, Dusty Plasmas : Physics, Chemistry and Technological Impacts in Plasma Processing (Wiley, Chichester, 1999).

[2] R. Roth, K. Spears, G. Stein, and G. Wong, Appl. Phys. Lett. 46, 253 (1985).

[3] G. Selwyn, J. Singh, and R. Bennett, J. Vac. Sci. Technol. A 7, 2758 (1989).

[4] Y. Watanabe, M. Shiratani, Y. Kubo, I. Ogawa, and S. Ogi, Appl. Phys. Lett. 53, 1263 (1988).

[5] A. Bouchoule, A. Plain, L. Boufendi, J.-P. Blondeau, and C. Laure, J. Appl. Phys. 70, 1991 (1991).

[6] A. Howling, C. Hollenstein, and P. Paris, Appl. Phys. Lett. 59, 1409 (1991).

[7] G. Jellum and D. Graves, J. Appl. Phys. 67, 6490 (1990).

[8] G. Selwyn, J. McKillop, K. Haller, and J. Wu, J. Vac. Sci. Technol. A 8, 1726 (1990).

[9] W. Yoo and C. Steinbrchel, J. Vac. Sci. Technol. A 11, 1258 (1993).

[10] B. Ganguly, A. Garscadden, J. Williams, and P. Haaland, J. Vac. Sci. Technol. A 11, 1119 (1993).

[11] B. Walch, M. Horanyi, and S. Robertson, IEEE Trans. Plasma Sci. 22, 97 (1994).

[12] A. Melzer, T. Trottenberg, and A. Piel, Phys. Lett. A 191, 301 (1994).

[13] C. Arnas, M. Mikikian, and F. Doveil, Phys. Rev. E 60, 7420 (1999).

[14] G. Morfill, H. Thomas, U. Konopka, H. Rothermel, M. Zuzic, A. Ivlev, and J. Goree, Phys. Rev. Lett. 83, 1598 (1999).

[15] A. Nefedov, G. Morfill, V. Fortov, H. Thomas, H. Rothermel, T. Hagl, A. Ivlev, M. Zuzic, B. Klumov, A. Lipaev, et al., New J. Phys. 5, 33.1 (2003).

[16] H. Rothermel, T. Hagl, G. Morfill, M. Thoma, and H. Thomas, Phys. Rev. Lett. 89, 175001 (2002).

[17] J. Dorier, C. Hollenstein, and A. Howling, J. Vac. Sci. Technol. A 13, 918 (1995).

[18] G. Praburam and J. Goree, Phys. Plasmas 3, 1212 (1996).

[19] J. Goree, G. Morfill, V. Tsytovich, and S. Vladimirov, Phys. Rev. E 59, 7055 (1999).

[20] D. Samsonov and J. Goree, Phys. Rev. E 59, 1047 (1999).

[21] V. Tsytovich, V. Vladimirov, G. Morfill, and J. Goree, Phys. Rev. E 63, 056609 (2001).
[22] M. Akdim and W. Goedheer, Phys. Rev. E 65, 015401 (2002).

[23] D. Jovanović and P. Shukla, Phys. Lett. A 308, 369 (2003).

[24] G. Gozadinos, A. Ivlev, and J.-P. Boeuf, New J. Phys. 5, 32.1 (2003)

[25] K. Avinash, A. Bhattacharjee, and S. Hu, Phys. Rev. Lett. 90, 075001 (2003).

[26] V. Tsytovich, G. Morfill, U. Konopka, and H. Thomas, New J. Phys. 5, 66.1 (2003).

[27] J. Goree, R. Quinn, G. Morfill, H. Thomas, T. Hagl, U. Konopka, H. Rothermel, and M. Zuzic, in Proceedings of the 4th Microgravity Fluid Physics and Transport Phenomena Conference, Cleveland (1998).

[28] M. Mikikian, L. Boufendi, A. Bouchoule, G. Morfill, H. Thomas, H. Rothermel, T. Hagl, A. Nefedov, V. Fortov, V. Molotkov, et al., in Dusty Plasmas in the New Millennium, edited by R. Bharuthram, M. Hellberg, P. Shukla, and F. Verheest (AIP, New York, 2002), p. 135.

[29] M. Mikikian, L. Boufendi, A. Bouchoule, G. Morfill, H. Thomas, H. Rothermel, T. Hagl, A. Nefedov, V. Fortov, V. Molotkov, et al., in Proceedings of the 29th EPS Conference on Plasma Physics and Controlled Fusion, Montreux, 2002, edited by R. Behn and C. Varandas (European Physical Society, Petit-Lancy, 2002), vol. 26B, pp. $\mathrm{O}-4.34$.

[30] M. Mikikian, L. Boufendi, A. Bouchoule, H. Thomas, G. Morfill, A. Nefedov, V. Fortov, and the PKENefedov Team, New J. Phys. 5, 19.1 (2003).

[31] M. Mikikian, L. Boufendi, and A. Bouchoule, in Proceedings of the 30th EPS Conference on Plasma Physics and Controlled Fusion, St Petersburg, 2003, edited by R. Koch and S. Lebedev (European Physical Society, Petit-Lancy, 2003), vol. 27A, pp. O-3.1B.

[32] J. E. Thomas, B. Annaratone, G. Morfill, and H. Rothermel, Phys. Rev. E 66, 016405 (2002).

[33] M. Akdim and W. Goedheer, Phys. Rev. E 67, 066407 (2003).

[34] A. Bouchoule and L. Boufendi, Plasma Sources Sci. Technol. 3, 292 (1994). 